\title{
O imaginário nas obras de Molina e Berega: (re)construindo signos
}

\section{Imagination in the works of Molina and Berega:} (re)constructing signs

AHLERT, Jacqueline ${ }^{1}$

BETENCOURT, Maria Goreti

\begin{abstract}
Resumo:
O presente artigo objetiva versar, de forma introdutória, sobre as representações simbólico-visuais que compõe as obras dos artistas Molina Campos e Berega, estabelecendo interfaces com obras do passado histórico da arte e propondo uma relação sígnica vinculada ao repertório iconográfico ocidental, como elemento constitutivo de imaginários sociais. Ambos os artistas, representaram os modos e as práticas cotidianas das pessoas no pampa sulino, tanto sul-rio-grandense quanto argentino, de um modo particular e semelhante. Propõese conduzir um discurso que reconfigure os imaginários manifestos nas obras, seus signos de ligação e as possibilidades emocionais que expressam, levando em conta a estética kitsch, presente nas representações analisadas.
\end{abstract}

Palavras chave: Imaginário, Representação, Kitsch

\footnotetext{
${ }^{1}$ Doutora em História pela PUCRS, docente do PPGH/UPF.

${ }^{2}$ Mestre em Comunicação e Semiótica pela PUCSP, doutoranda em História pelo PPGH/UPF.
} 


\section{Abstract:}

This article aims to introduce the symbolic and visual representations that make up the work of the artists Florencio Molina Campos e Luiz Alberto Pont Beheregaray ("Berega"). Their work possesses linkages with important works from art history and Western iconography, and has been an important element in the construction of social imagination. Both artists portrayed theeveryday lives of inhabitants of the southern Pampas region in the Brazilian state of Rio Grande do Sul as well as Argentina in manners both similar and unique.This article proposes to reconfigure the imaginations contained within their works, their symbolic linkages, as well as the emotive aspects they express, all taking into to account their inherent Kitsch aesthetic.XXX

Keywords: Imaginary, Representation, Kitsch

\section{Introdução}

O artigo propõe uma construção narrativa sequencial a partir de obras dos artistas Florencio de Los Angeles Molina Campos, conhecido como Molina Campos e de Luiz Alberto Pont Beheregaray, o Berega. Objetiva-se uma leitura de sentido dos signos que representam aspectos do imaginário presente nas obras de ambos, por meio de interfaces destes com produções artísticas do passado histórico. Para tanto, o estudo ancora-se nas concepções teóricas de Bronislaw Baczko, no que tange ao imaginário social, de Roger Chartier, ${ }^{3}$ no âmbito da representação, e nas diretivas de análise da semiótica peirciana. ${ }^{4} \mathrm{O}$ texto apresenta-se organizado em três partes:os modos de representação simbólicos que se constroem mediante signos de sentidos

\footnotetext{
3 Será o conjunto de representações, segundo Baczko, que caracterizará a noção de imaginário. O qualificativo social, empregado pelo autor, remeterá o conceito ao conjunto da população, ou pelo menos a um grupo específico no interior de determinada população.

${ }^{4}$ Os conceitos de signo, índice e símbolo aqui utilizados estão relacionados as definições semióticas de Charles Sanders Pierce. Signo refere-se a tudo aquilo que não é o próprio objeto, que em certa medida ou sob algum aspecto, representa alguma coisa para alguém; índice é um signo que é um indicador. Relaciona-se efetivamente com o objeto, por contiguidade, por associação; Símbolo é o signo que referese ao objeto que denota em virtude de uma legitimação, e portanto, é histórico e convencionado. Cf. SANTAELLA, Lucia. Semiótica aplicada. São Paulo: Cengage Learning, 2002.
} 
comuns à cultura ocidental; as especificidades biográficas e estéticas dos artistas mencionados e a dinâmica da representação a partir das socializações festivas, das confrarias - no âmbito do pertencimento social -, e por fim, das questões associadas a virilidade e ao poder.

O repertório é explorado sob o viés de elementos psicológicos, que criam uma rede de representações sígnicas, resultando em um imaginário genérico. Contudo, além do potencial das representações para urdir imaginários, o estudo prioriza também o contexto estético em que as obras enquadram seus signos, na perspectiva da teoria estética do kitsch.

Para além da conotação pejorativa de uma arte "vulgar" ou de "barbárie estética", compreende-seque a pseudo-arte do kitsch corporifica a sensação de trazer beleza para o cotidiano, sustentada por um sistema hedonista de prazer imediato. Esse caráter coletivo, mormente, é ecoado pelos signos no imaginário social.

De acordo com Lipovetsky, o que impulsiona o Kitsch é o influxo de uma cultura da "felicidade", marcada pelo "desregulamento das hierarquias culturais,com a erosão da diferença entre o high e low art, todas as estéticas ganham direito de cidadania, tudo se torna possível e legítimo" (LIPOVETSKY, 2015, p. 310).

Neste sentido, Molina e Berega possuem pontos de convergência. O que os vincula ao Kitsch é a série de calendários criados por ambos, em que destacam-se características costumbristas, usos e costumes da sociedade campesina localizada nos pampas ${ }^{5}$ do Brasil e da Argentina.

Tendo como suporte os calendários - veículo de comunicação de massa, sem custos para os usuários e de fácil acesso -, suas ilustrações transcenderam as galerias de arte e, expostas no interior das casas, deram aos anuários uma função decorativa, mais do que puramente informativa. Portanto, que contextos associativos poderiam ser acionados pelas imagens nos sujeitos que recebiam e ressignificavam seus cotidianos naqueles trabalhos?

\footnotetext{
${ }^{5}$ O pampa é uma região pastoril de planícies com coxilhas localizada no sul da América do Sul. Abrange a metade meridional do estado brasileiro do Rio Grande do Sul, o Uruguai e as províncias argentinas de Buenos Aires, La Pampa, Santa Fé, Córdoba, Entre Ríos e Corrientes. Ver: MORRONE, J.J. América do Sul e geografia da vida: Comparação de algumas propostas de regionalização. In: CARVALHO, C.J.B., Almeida, E.A.B. (eds.). Biogeografia da América do Sul: Padrões e processos. São Paulo: Editora Roca, 2011.
} 
As especificidades de uso dos calendários direciona-os a uma produção de fácil compreensão, em que convenções e simulacros, configuram-se na estética kitsch. Para atingir um público amplo, interessado nesta experiência, o produto kitsch, compôs-se de insígnias comuns, sendo que o seu caráter "globalizador"procura pelo gostocomum, formado pelas massas consumidoras de produtos similares (AHLERT, TORTATO, 2015). Nesta configuração se insere o repertório visual criado a partir da iconografia ocidental, numa rede de representações e de significações.

\section{O imaginário nas representações}

Nunca olhamos uma coisa apenas, estamos sempre olhando para a relação entre as coisas e nós mesmos (BERGER, 1999, p. 11).

Pertence ao campo das ações humanas fabricar objetos e contar histórias. Muitas vezes essas duas ações estão associadas, os objetos criados fazem parte de uma construção imaginária que inclui na sua feitura relativa subjetividade. Para pintar uma paisagem, por exemplo, o artista recorta de um espaço real uma imagem que será reproduzida em um outro suporte, desconexo da paisagem em si, porque além do meio, envolve tinta, tela, químicos, entre outros. Finalmente, o que será reproduzido, embora muito próximo daquele real, não é de fato real, se não apenas um recorte feito de um material completamente alheio ao qual o olho retirou o conteúdo (Cf. SANTAELLA, 2010).

No entanto não é qualquer imagem que tem a capacidade de impressionar e se reproduzir em cadeias significativas, elas devem constituir um conjunto não ordinário e sim extraordinário. O que quer dizer isso? Que uma imagem para produzir impacto na mente humana e se constituir em uma outra realidade,deve estar além do que é coloquial, configurando uma rede de signos igualmente extraordinários, que se ligam ao nosso ordinário cotidiano a fim de apreendermos seu significado e os discursos que carregam enquanto representação. Essas narrativas não são neutras, "produzem estratégias e práticas tendentes a impor uma autoridade, uma deferência, e mesmo a legitimar escolhas" (CARVALHO, 2005, p. 149). 
Neste âmbito, a importância do "belo" fica pormenorizada frente ao impacto que a representação gera na rede de significações. O sujeito, "na sua qualidade de ser sensível, é muito menos guiado por princípios generosos do que por objetos imponentes, imagens chamativas (...), emoções fortes" (BACZKO, 1984, p.302). O autor expõe o que é proeminente enquanto representação para a mente humana, em síntese o percebido na fruição estética seria o "sobre-humano", o mais humano que humano, no uso do termo feito por Nigel Spivey (2005). Isso não direciona a uma oposição do real, mas a uma série de sobreposições que conjugam constituições sociais, práticas culturais e percepções psicológicas. As representações "se constituem através de várias determinações sociais para, em seguida, tornarem-se matrizes de classificação e ordenação do próprio mundo social, do próprio real" (CARVALHO, 2005, p. 151).

É próprio da função do símbolo a representação de algo que está ausente. Sua criação e seu uso estão, deste modo, intrinsecamente vinculados a algo que não está e deve se fazer presente através de signos metafóricos, que afiançarão sua memória. Imagens, em sua potencialidade de representar o faltante, munem-se de novos signos que não faziam parte do objeto, conceito ou pessoa de origem. Deste modo, há uma distinção entre o representado ausente e a imagem que o representa. Ao fazer um ausente presente pela imagem, também se está configurando um conjunto imaginário que traz um novo personagem, totalmente simbólico.

Para Chartier (1991, p.184) a representação apresenta duas características: fazer ver uma ausência e apresentar uma presença. Na primeira, aparecem signos que remetem ao personagem ausente, não necessariamente como uma imagem realística, mas como um conjunto de coisas, sejam formas, cores, configurações, que atestam aquele personagem ou que "representam o personagem". Na segunda,os signos escolhidos funcionam como registro simbólico, que deve ecoar na mente do sujeito que frui.

\footnotetext{
Aquém dos pensamentos claros e muitas vezes apesar deles - as representações e as ações; supõe uma eficácia própria às ideias e aos discursos, separados das formas que os comunicam, destacados das práticas que, ao se apropriarem deles, os investem de significações plurais e concorrentes (CHARTIER,1991, p.188).
} 
A maneira como interpretamos as mensagens está diretamente relacionada com a quantidade e qualidade de signos que dada sociedade produz e reproduz, ligada as suas crenças, costumes, tradições etc. De modo ilustrativo, pode-se ponderar sobre a ideia de "demônio"assimilada pela cultura ocidental. Sua origem remonta a Antiguidade e, sobretudo, o período medieval, onde imagens estilizadas do personagem eram francamente reproduzidas. Mesmo que, contemporaneamente, o impacto não seja o mesmo, remanescem nas imagens o conjunto sígnico que requer um significado relacionado ao demônio. Assim, a reação que se tem às imagens não se dá puramente pelo processo mecânico do olhar e da luz, senão pelo componente simbólico que as imagens demandam. Além do que, o olhar é um ato de escolha.

\section{Molina e Berega: representações do pampa e de seus atores sociais}

O argentino Florencio de Los Angeles Molina Campos (1891-1959), passou a vida entre a cidade de Buenos Aires, onde nasceu, e as propriedades da família, em Tuyu e General Madariaga, na província de Buenos Aires, e Chajarí, província de Entre Rios. Pintor e desenhista, é reconhecido pelas figurações caricaturais, ilustrativas das práticas dos habitantes dos pampas argentinos, popularmente conhecidos como gaúchos ${ }^{6}$. As ilustrações de Molina, formam um conjunto conectado pelo "gauchismo" nelas expresso, como constituinte de modos de vida e relação com o espaço campesino. Em 1931, a fábrica Alpargatas, lançou uma campanha publicitária tendo como suporte um calendário ilustrado por Molina Campos. As edições prosseguiram pelos períodos de1931 a 1936, 1940 a 1945, 1961 e 1962 e se constituíram em seu trabalho mais difundido. ${ }^{7}$

Outra série de calendários foi produzida para empresa norte-americana Mineapolis-Moline, entre 1944 e 1958. Os almanaques eram similares aos da firma

\footnotetext{
${ }^{6}$ Não é objetivo deste artigo uma análise crítica sobre a concepção de "cultura gaúcha". Para aprofundar - tema ver: GOLIN, Luis Carlos. Reflexos entre o gaúcho real e inventado. http://www.ufrgs.br/difusaocultural/nosoutrosgauchos/assets/encontros/arquivo/reflexos_entre_o_gaucho_ real_e_o_inventado_i_nos_os_gauchos.pdf

${ }^{7}$ Ver: http://www.molinacampos.net/molina-campos-vida-y-obra
} 
Alpargatas, porém algumas imagens incluíam o maquinário agrícola fabricado pela contratante.

A obra e biografia de Berega (1934-2012), aproximam-se das de Molina. Nascido na cidade fronteiriça de Uruguaiana, no Rio Grande do Sul, residiu grande parte da vida em Porto Alegre, retornando, nos últimos anos de vida, a sua cidade natal para exercer atividades pecuaristas. Seu trabalho também contempla a temática gauchesca, a memória das estadias, do gaúcho campesino, seus hábitos e mitos. Berega teve suas obras reproduzidas em calendários para a Petróleo Ipiranga S.A, entre 1979 e 1999. As imagens representam, caricaturalmente, o gauchismo sul-riograndense, em vários momentos aos moldes de Molina, com humor e ironia e, em outros, como uma catalogação visual detalhada daquilo que ficou conhecido como "tradição gaúcha".

Ambos calendários passaram a enfeitar paredes de casas, instituições, bares e demais locais, adentrando a ambiência cotidiana das pessoas.

\section{Pareando significados: a festa}

A arte proporciona um reconstante olhar sobre. Não é incomum que um mesmo tema ou ideia assuma novas formas, mantendo discurso similar, mesmo que com alterações compositivas evidentes. Em alguns casos isso caracteriza uma releitura muito clara, em outros, são simplesmente signos que estão presentes no repertório imagético humano e que reaparecem em outro contexto, porém trazem uma memória subjacente.

Ao observar algumas obras de Molina Campos, independente de análise formal ou simbólica, apenas como representação de um cotidiano típico e de um determinado tempo e lugar, poder-se-á considerar que há uma sequência sígnica que, em outro contexto, ofereceu igual olhar à outras imagens, anteriores a ele. 
Figura 1: Almuerzo - El santo de la patrona.

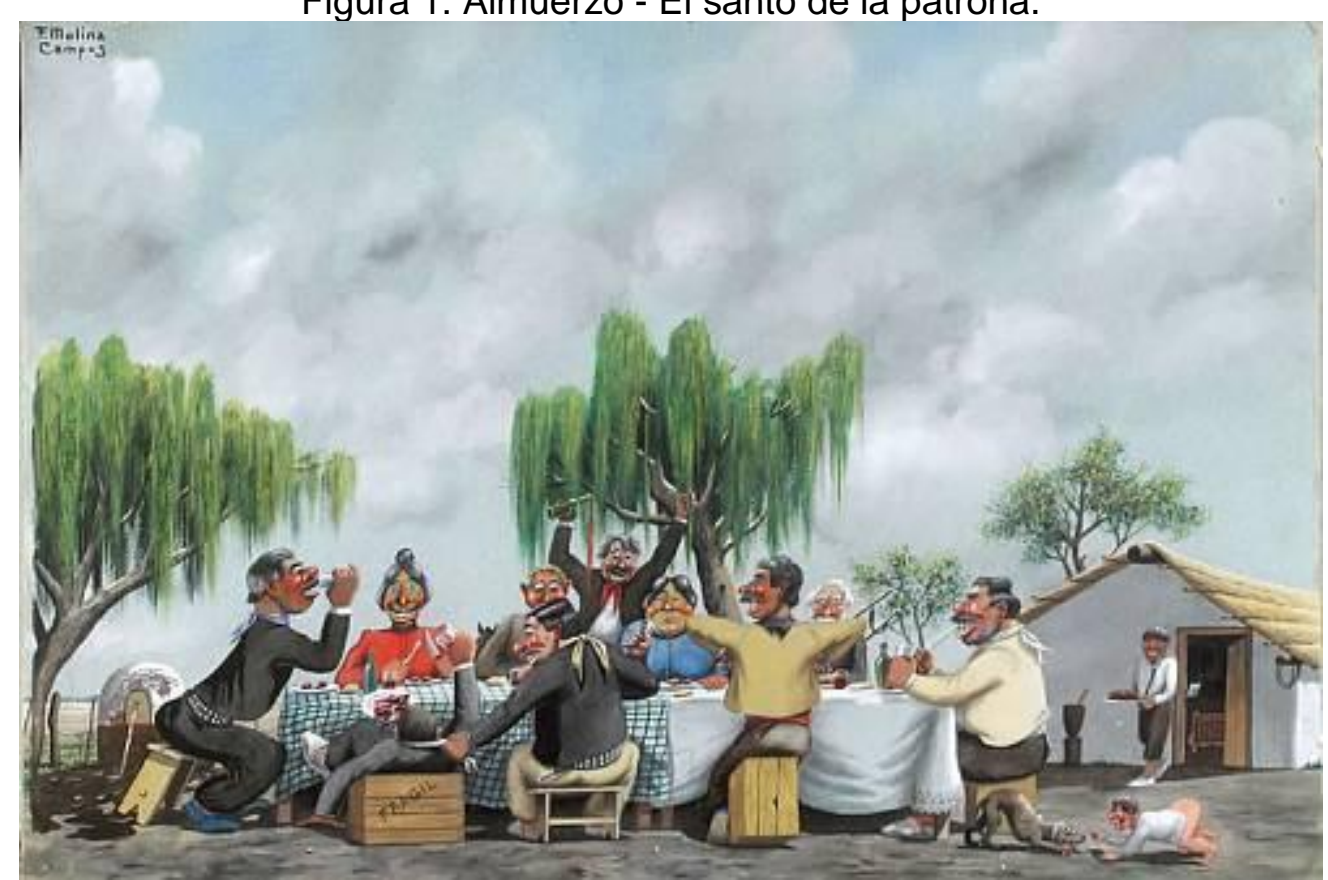

Ilustração de Molina Camós para o Almanaque Minneapolis Moline, 1944.

Fonte:https://goo.gl/OgAckT

A obra de Molina, "Almuerzo - El santo de la patrona" representa uma cena de refeição ao ar livre, uma comemoração - indicada pelos gestos eufóricos -, reunindo familiares, amigos e/ou vizinhos. Enfim, suscita no imaginário social uma aproximação com o que se vivencia frequentemente em festas ou reuniões familiares, pertence à ambiência dos sujeitos, e portanto, é confortável. Significações similares são acionadas na ilustração "Cidade de lona", de Berega. Nela o artista utiliza-se de signos de efemeridade, evidenciados pela situação de acampamento, todavia, mantém a mesa como elemento aglutinador, em torno do qual a socialização ocorre. 
Figura 2: Cidade de Lona.

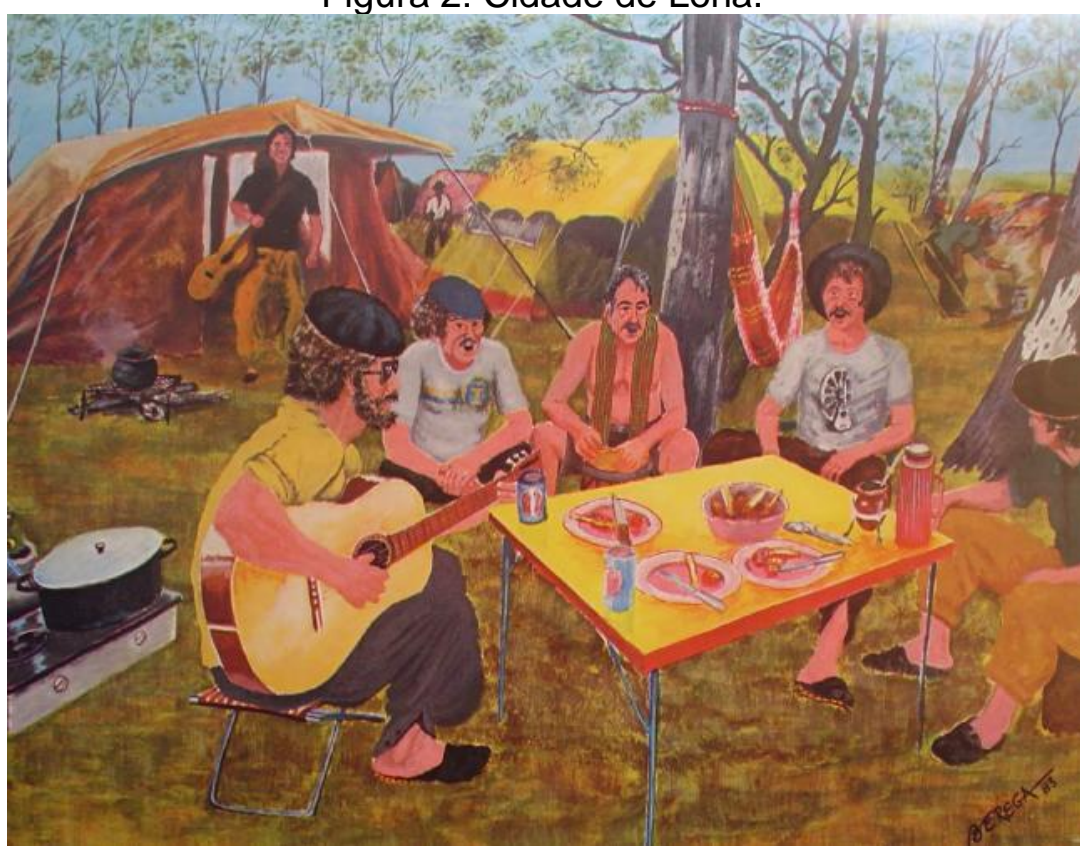

Ilustração de Berega para o Calendário Ipiranga, 1986. Fonte: https://goo.gl/QhhPN9

Assim, é importante uma maior aproximação com a questão da experiência estética produzida pelo indivíduo, em particular, e a que é encontrada nos contextos de convívio social, onde a experiência ocorre. A produção de discursos gerada por uma sequência de signos (que possuem correspondência no imaginário social daquele grupo), passa a ser ao mesmo tempo fruída e coproduzida, uma vez que o sujeito continua demando significados para aquele objeto específico.

É relevante observar como o aspecto da reunião festiva, do convívio, traz uma lembrança análoga em quem quer que a observe. Os signos expressos, como as pessoas em torno da mesa, sentados em caixotes que fazem as vezes de cadeiras, em um ambiente aberto, fora de casa, remetem a uma situação prazenteira, nada para ser pensado com grande cuidado ou explicado com grande apuro.

Há uma interação presente nas formas como os personagens se olham ou para o que olham, pode-se sugerir um tipo de conversa trivial ou o entoar conjunto de uma canção por todos conhecida. A disposição dos personagens, a presença ou espera pela comida, os talheres sobre a mesa, a bebida, etc. expressam um cenário de familiaridade, de pertencimento. 
Em inúmeras obras de arte, há referências do ordinário que utilizam signos compositivos semelhantes, mas atendem a outros conceitos, como a festa propriamente dita.É o caso da obra o "Casamento dos camponeses", de Pieter Bruegel, o Velho, pintada na Holanda em 1568. Nela está figurada uma cena cujos camponeses são protagonistas, em um período que eram comuns as representações da realeza ou do clero - enfraquecidas as composições religiosas pela emergência do protestantismo-, Bruegel centraliza o camponês anônimo, dá a ele o contorno do ator principal.

Figura 3: Casamento dos camponeses

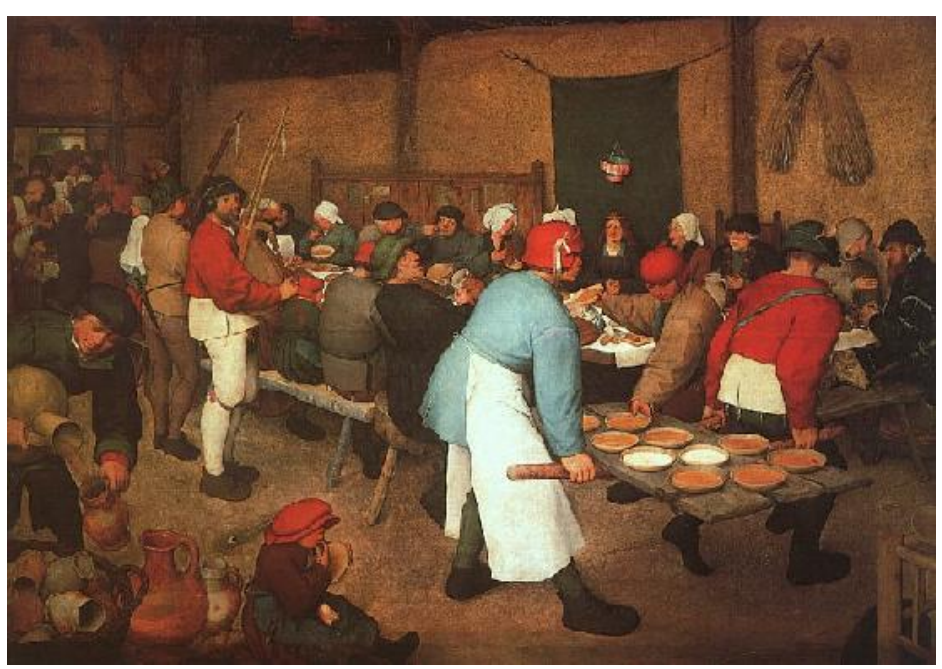

Pieter Bruegel, 1568. Fonte: Kunsthistorisches Museum Wien. In: https://goo.gl/YGM9ti

Em vários momentos há um tom de sátira na obra de Bruegel, assim como observa-se claramente nas obras (de modo geral) de Molina e Berega. Também é possível conjecturar um tom kistch na obra do neerlandês, especialmente quanto traz à tona os sentimentos mais corriqueiros, advindos dos risos, da bebedeira, da alegria e até de constrangimentos que o cotidiano pode proporcionar.

Através dos seus imaginários sociais, uma coletividade designa a sua identidade; elabora uma certa representação de si: estabelece a distribuição dos papeis e das posições sociais. Exprime e impõe crenças comuns, constrói uma espécie de código de "bom comportamento" designadamente 
através das instalações de modelos formadores tais como o "chefe", o "bom súdito",ou o guerreiro corajoso" etc. (BACZKO, 1984, p. 309).

Neste caso, como assegura Baczko, é produzida uma representação global da sociedade ao qual o indivíduo pertence, ele reconhece os signos e os perpetua criando inclusive as relações pessoais a partir dos signos pré-estabelecidos. Sendo assim o imaginário social uma espécie de força reguladora. ${ }^{8}$

Não é importante saber se Berega e Molina conheciam ou não a obra "Casamento dos camponeses", porque o fundamental reside no imaginário que permeia as representações, como uma estratégia emocional que aciona identificação nos observadores. Nesse viés, um sentimento kitsch afeta as três obras, o que as torna aprazíveis e próximas ao observador.

Umberto Eco traz algumas definições importantes sobre o kitsch, opondo de certa forma, a visão pejorativa dessa estética. Na segunda metade do século XIX, os turistas americanos, desejando comprar obras mais baratas em Munique, pediam um desconto (sketch), ou seja quinquilharias baratas para experiências estéticas fáceis. Porém, já havia o verbo Kitschen para denotar "varrer a lama" ou "lixo das ruas", assim como maquiar móveis velhos para parecerem novos, ou ainda, com o significado de vender barato (2007, p.294).

Deste modo, o kitsch foi usado como uma forma de descartar determinados tipos de representação estética que ficavam fora da "grande arte" ou da cultura erudita. Não necessariamente, "feios" ou de o mau gosto. Afirmar isso seria pressupor que existe um gosto certo, como uma religião certa ou uma orientação sexual certa.Conforme argumenta Eco, para os cultores de uma arte "culta" o kitsch é kitsch, para os cultores do kitsch, está em igual escala àquelas das expostas em museu.

O âmago do kitsh estaria em representar,seja em qualquer variedade plástica em que foi plasmado, uma forma de sentimento considerado fácil ou "compassivo".

\footnotetext{
${ }^{8}$ Outras pinturas que evocam um grupo de pessoas em torno da mesa são: The Potato Eaters, de Vincent van Gogh; As the Old Sing, So Pipe the Young, de Jan Steen; The Children of Elizabeth De Peyster and Charles Willson Peale, de Charles Willson Peale, entre inúmeros outros exemplos que não cabem aos desígnios do artigo.
} 


\begin{abstract}
Se uma das definições do kitsch o vê como algo que visa provocar um efeito passional em vez de permitir uma contemplação desinteressada, uma outra considera o kitsch a prática artística que, para nobilizar-se e nobilizar o comprador, imita e cita a arte dos museus.....ao fazer arte, a vanguarda evidencia os procedimentos que levam à obra e os elege como objetos de seu próprio discurso, enquanto o kitsch evidencia as reações que a obra deve provocar e elege como objetivo da própria operação as reações emocionais do fruidor" (ECO. 2007.p. 397).
\end{abstract}

A aversão ao sentimentalismo vem da ideia de que é inferior. "Sentimentalismo" e kitsch "têm algo a ver com a degradação geral dos sentimentos e seu significado" (SOLOMON, 2004, p 241). Na cultura visual, seria o contraponto clássico, racional de um Jaques Louis David com a emocionalidade de um WilliamAdolphe Bouguereau. A arte desenvolvida entre o neoclassicismo e o realismo, circula pelo universo da emocionalidade, proposta pelo romantismo, que tem como antecessor estético o rococó, emocionalmente sentimentalista e não necessariamente sentimental (emocional). Assim entendido como uma arte bem produzida, materialmente falando, porém "brega" na concepção e, portanto, menos importante ou impactante.

Independente da carga emocional que carregam no seu repertório iconográfico, as representações Kitsch não fogem de constituirem-se como discursos de poder e, em certa medida, dominação. Como mencionado a cima, não há neutralidade na representação, são intrínsecas à ação que o signo desencadeia no observador as estratégias e práticas que visam estabelecer um comando e mesmo legitimar escolhas (CARVALHO, 2005, p. 149).

Por este viés, entende-se que as ressignificações que resultam de se ler os discursos em um dado sistema cultural também vão construir formas igualmente imperiosas de entendimento dos novos signos (ressignificados). De forma que, não se foge da lógica estabelecida por uma dada cultura, ao relê-la os signos antigos incorporaram a novos, porém sem perder o princípio norteador. É possível que esse aspecto que traga conforto ao leitor, há uma forma de continente nisso tudo que abarca e dá identidade ao sujeito. Como explica Baczko,

O imaginário social torna-se inteligível e comunicável através da produção dos "discursos" nos quais e pelos quais se efectua a reunião de 
representações coletivas numa linguagem. Os signos investidos pelo imaginário correspondem a outros tantos símbolos. $E$ assim que os imaginários sociais assentam num simbolismo que é, simultaneamente, obra e instrumento (BACZKO, 1984, p. 311).

Essas motivações são, majoritariamente, da ordem psíquica. O sistema simbólico é construído no bojo da subjetividade humana, porém está alicerçada sobre um construto já dado. Assim, as experiências coletivas aproximam-se dos desejos coletivos. A festa, a reunião, a regozijo da participação são compreendidos tanto na obra de Bruegel quanto de Molina e Berega, pela essência da motivação ser a mesma. Portanto, kitsch na acepção. Cada signo reproduzido, mesmo representado um tempo e um grupo social em particular, remete a significados similares.

Os imaginários sociais e os símbolos em que eles assentam "fazem parte de sistemas complexos e compósitos, tais como, nomeadamente, os mitos, as religiões, as utopias e as ideologias" (BACZKO, 1984, p. 312). Neste caso, a relação com o kitschse dá, não como um produto em particular, e sim na emocionalidade produzida pela obra em questão.

Há um sentimento kitsch nas obras mencionadas, seja em Bruegel, no tom jocoso e ousado de representar um momento de coletivo emocional, no casamento de camponeses e na valorização do riso na festa, seja em Molina e Berega. O conceito do que está representado sobressai-se, perpassando pelo efeito kitsch, porquanto transparece uma emoção não do caráter do sublime, senão do pitoresco.

O conjunto constrói uma representação do imaginário social, pois

[...] os sistemas simbólicos em que assenta e através do qual opera o imaginário social são construídos a partir da experiência dos agentes sociais, mas também a partir dos seus desejos, aspirações e motivações (BACZKO, 1984 p. 311).

Em vários momentos há um tom de sátira na obra de Bruegel, como percebese na ilustração do argentino Molina, enquanto Berega explora mais a expressividade confraterna. Ainda assim, ponderando a nuance kitsch das imagens, que traz à tona memórias afetivas - considerando que não há memória a-emotiva -, é possível 
identificar um imaginário representado por esquemas sígnicos comuns às obras supracitadas.

\section{Pareando significados: a posteridade}

Outro componente seguidamente representado é o sentimento de perpetuação. Em "Posando para a Posteridade" de Berega, um grupo de homens vestidos com a tradicional indumentária gaúcha - bombacha, lenço chapéu e botas -, se posiciona para o registro.Constituem uma confraria, "Sociedade Cultural e recreativa? Flor e Truco", 9 identifica-os a escrita na parede. Trata-se de um grupo social que se reúne sob a égide do entretenimento, mas também tem cunho cultural. $\mathrm{O}$ que pode indicar isso?

O termo "cultural" presente na imagem associa-se a conhecimentos e práticas singulares perpetradas pelo grupo. Posto que a própria frase está escrita com letras invertidas, a referência não é a erudição cultural. A grafia é constitutiva do caráter cultural do grupo, padrões criados e transmitidos de valores, ideias e outros sistemas significantes do ponto de vista simbólico.

O ponto de interrogação no final do título, também pode ser um indicativo do aspecto jocoso e bem humorado que o artista coloca em suas obras. Talvez seja realmente uma pergunta, isto é uma sociedade de cultura? Neste caso, erudita? Ou um grupo que se reúne para jogar truco? A palavra flor figura a serviço do que? Podese inferir apenas que a flor suavizaria, denotaria uma compleição feminina, e um componente mais lúdico e, portanto, mais infantil nesses homens, ao passo que os torna sujeitos conformados em uma sociedade que possui regras e normas.

O fato de estarem todos frontalmente posicionados, uns sentados e outros em pé, pernas cruzadas,mãos postas no colo ou escondidas, mas todos amplamente

\footnotetext{
${ }^{9}$ Berega esclarece sobre a imagem: Campeões de Truco e Rinha, vice de Tava e menção honrosa de Bocha, foi a premiação que a "Flor e Truco", obteve no último "Rodeio Literário, Desportivo e Recreativo". A sede social funciona provisoriamente nos fundos do bolicho "El Sapo Milonguero", do basco Etcheveray. A Sociedade, na verdade, é bem mais recreativa que cultural, mas quem sabe se entre seus componentes não estará um futuro membro de alguma insigne Academia de Letras, um político de renome ou um distinto presidente do Clube Comercial. Quem viver, verá! In: http://www.berega.com.br/obras/calendariosframes.htm. Acesso em 10.abr.2017
} 
manifestos e bem organizados, remete a um esquema coletivo de interpretação das experiências individuais, "tão complexas quanto variadas, uma codificação das expectativas e das esperanças" (BACZKO, 1984, p. 311).

Caricaturalmente, os rostos dos personagens identificam diferentes matrizes étnicas, numa alusão ao universo híbrido da fronteira e do arranjo histórico que personificou o gaúcho.

Molina não deixou de representar as guildas sulinas, mas diferente de Berega, postou os personagens de modo intimidador, com feições mais uniformes, vestindo bombachas e chiripás, ${ }^{10}$ chapéus,botas e sapatos de pano ou couro, comumente denominados "alpargatas". Postados frontalmente, os homens, cujas feições alternamse entre os olhares carrancudos ou dispersos e os sorrisos largos, têm suas personalidades preconizadas. Suas funções sociais estão sinalizadas na imagem, são homens da lida campesina, os cavalos pastam em uma sombra a direita do grupo, ao lado de uma edificação que marca sua ancoragem naquela paragens.

As agremiações, sociedades e corporações representadas em telas constituem um gênero de pintura, denominado Retrato Pictórico, tendo como subgênero os Retratos de Grupo. Indivíduos reunidos sob a proteção de um coletivo são tema frequente na História da Arte, a exemplo das obras "A Ronda Noturna" e a "A agremiação dos tecelões", de Rembrandt van Rijn; "Regentes do hospital St Elizabeth de Haarlem" e "Companhia do capitão Reynier Reael", de Franz Hals; "Anunciação com três Avogadri" e Membros da Scuola Grande di San Marco (Aparição de São Marcos), de Domenico Tintoretto, entre inúmeras outras. De modo geral, seguem composição e objetivos semelhantes e, portanto, estão na mesma categoria sígnica, de sujeitos que são irmanados pela sociedade a qual estão representando.

Esse tipo de retrato, oferece aos grupos uma qualificação especial diante de outras pessoas. Podem não ser nobres ou sacerdotes, mas se diferenciam de seus concidadãos porque pertencem a uma corporação. São similares aos selfies, que reproduzem o desejo humano de perpetuação, mas também de ser visto e lembrado presentemente.

10 Peça de vestuário utilizado pelos homens do campo, sul-rio-grandenses, argentinos, uruguaios e paraguaios, que consiste num retângulo de pano, passado entre as coxas e preso à cintura. 


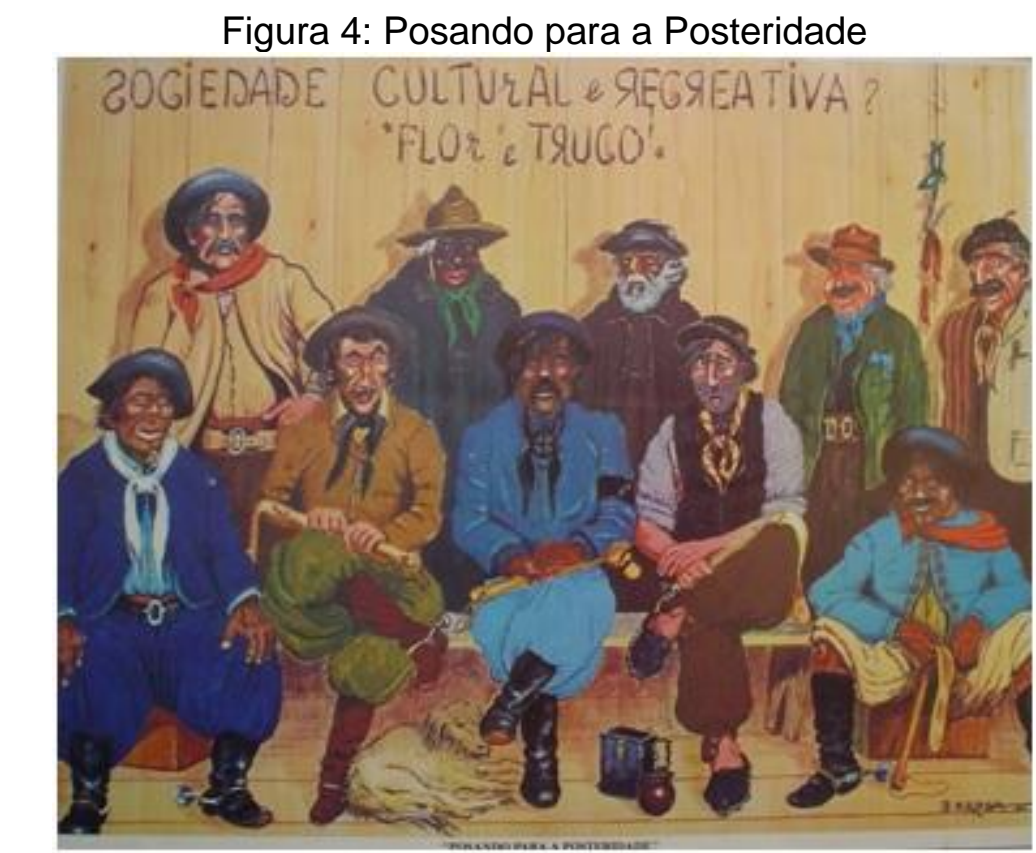

Ilustração de Berega para o Calendário Ipiranga, 1983. Fonte: https://goo.gl/kOYoFH

Figura 5: Sudiadanoj!

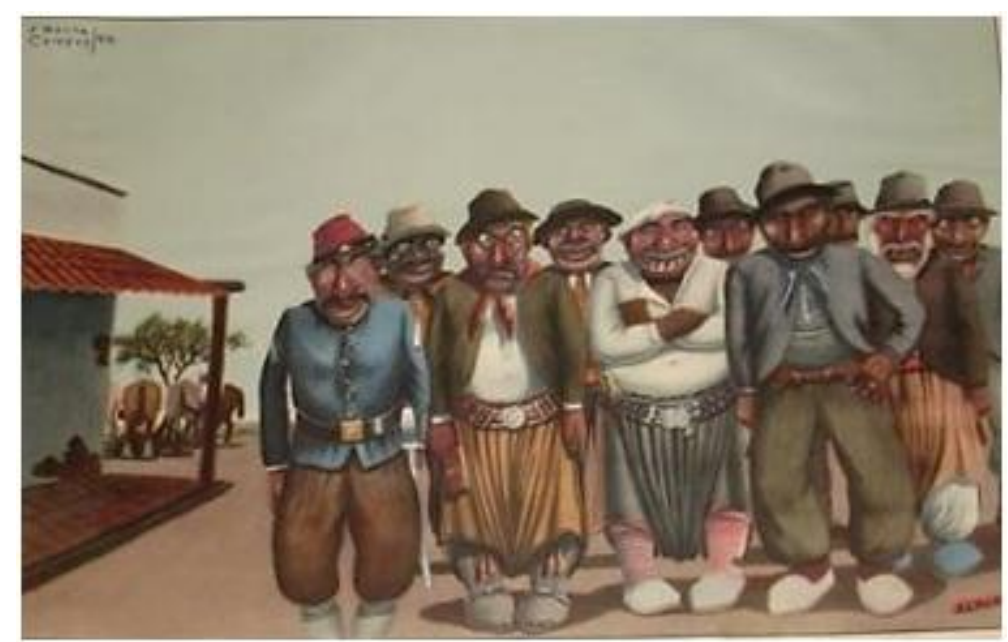

Ilustração de Molina Campos para o Almanaque Alpargatas, 1943.

Fonte: https://goo.gl/BXO09R

Os desejos de se ver e de ser visto são sistematicamente perceptíveis em imagens na cultura ocidental desde a Antiguidade, objetivando a representação imaginária da perpetuação de si pelo universo simbólico. Nas obras de Frans Hals, 
Tintoretto, Berega e Molina todos os personagens posam. Em suma, o objetivo é que todos apareçam, mesmo que aparentemente haja ares de que foram flagrados "sem querer" em suas atividades, seja em uma charla (conversa), oração ou estudo.

Enquanto representação, inserem-se em campos discursivos onde as imagens atuam como argumentos de distinção e exibem relações de poder entre os retratados e, sobretudo, para com os espectadores. Implicam no posicionamento do eu e, consequentemente, na negociação continuada de identidades sociais (CHARTIER, 2009).

Figura 6: Membro da Scuola Grande di San Marco. Aparição de São Marcos ${ }^{11}$

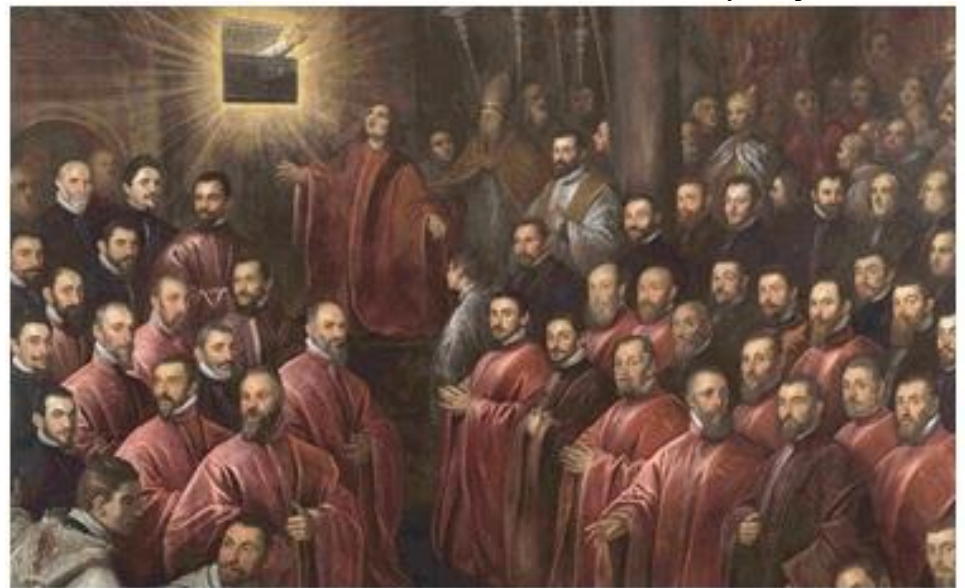

Domenico Tintoretto, 1600-1610. Fonte: https://goo.gl/9nTCdl

\footnotetext{
${ }^{11}$ A obra faz parte da série de Tintoretto sobre São Marcos, registrando o momento em que o corpo desmembrado do santo se revela na Basílica de San Marcos, na forma de uma mão emergindo da parede, envolta por um brilho intenso. Um incêndio, em 976, destruiu a primeira igreja dedicada a São Marcos e, em 1063, o Doge Contarini construiu no local uma basílica. Quando a nova igreja foi concluída em 1094, o corpo do santo não pôde ser localizado. Temia-se ter sido consumido pelo fogo, em 976. Durante um encontro dos membros da igreja para oração, um dos braços de São Marcos teria surgido no lado sul da igreja, revelando o que viria a ser uma relíquia sagrada. Testemunhando a cena, estavam senadores venezianos e confrades (membros) da Scuola Grande di San Marco, contemporâneos do artista. Tradução das autoras. In: SAVE VENICE INC. Disponível em: https://savevenice.org/. Acesso em 20.mar. 2017
} 
Figura 7: Regentes do hospital St Elizabeth de Haarlem

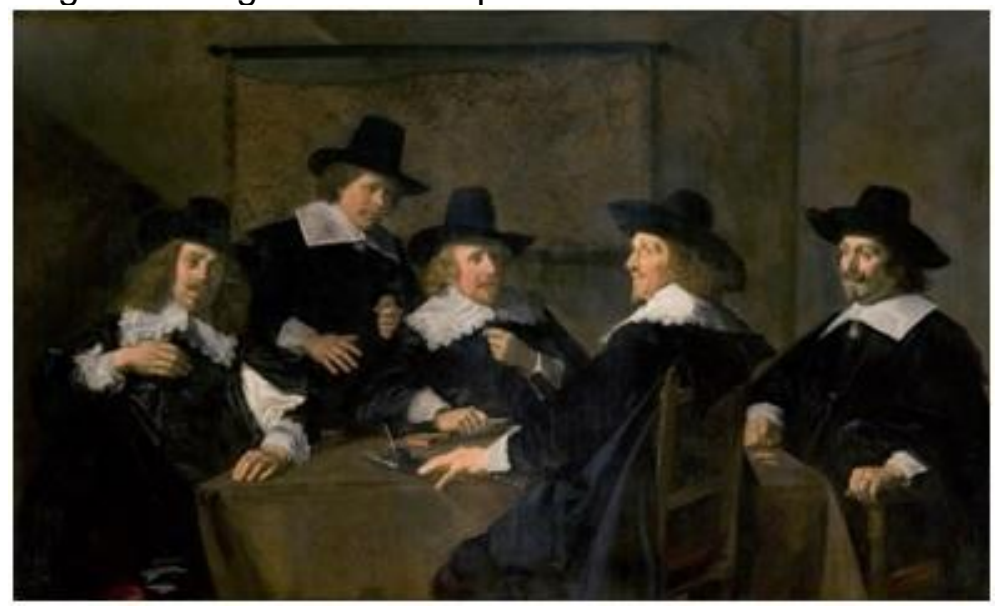

Frans Hals, 1641. Fonte:https://goo.gl/89Po0a

\section{Pareando significados: a virilidade}

Vai ficando para trás, salvo nas grandes estâncias, o domador de profissão, o verdadeiro ginete. O grito de "larga", o tapa na orelha, o relincho de dor e raiva, a trovoada do rebenque, o risco da espora e o atávico e selvagem grito do ginete, sinal de vitória e posse. Entre um e outro corcovo, o movimento rítmico fundindo, plasmando, duas figuras numa só: o centauro (BEREGA, 1982, s/n. In:https://goo.gl/Frl71s).

A última referência diz respeito a um signo muito caro ao universo pampiano, o homem e seu cavalo. Entre as interpretações possíveis, o cavalo sinaliza a virilidade e força, além do sentido de liberdade que integra seu porte e movimento.

Em posse do cavalo, o homem parece adquirir parte da pujança $e$ magnificência projetada no animal. É componente do rol simbólico-identitário sul-riograndense a imagem do ginete sobre o cavalo. Comumente, o animal figura com as patas dianteiras erguidas, enquanto o cavaleiro curva seu tronco para equilibra-se e manter o domínio, ao passo que segura as rédeas com uma mão e o chicote com a outra, exercendo com violência sua autoridade sobre o bicho. 
Nas ilustrações de Molina e Berega, os cavalos aparecem em movimento,resistindo a doma e em franco duelo com o peão, ao passo que este controla o animal mantendo os pés firmemente presos aos estribos, as rédeas na mão esquerda e o açoite na direita. Os montadores revelam total domínio técnico,por meio do qual percebe-se um poder simbólico sobre o animal. A ideia de que o homem e o cavalo compõe um mesmo personagem, o centauro,permeia o imaginário ocidental desde os gregos. Euclides da Cunha, em Os Sertões, refere-se ao gaúcho como o "pealador valente (...), precipitando-se, ao ressoar estrídulo dos clarins vibrantes, pelos pampas, com o conto da lança enristada, firme no estribo; atufando-se loucamente nos entreveros"([1902] 2001, p.53). A imagem criada pelo escritor tem conotação romanesca do homem do sul e, portanto, kitsch.

Figura 8: Gineteando

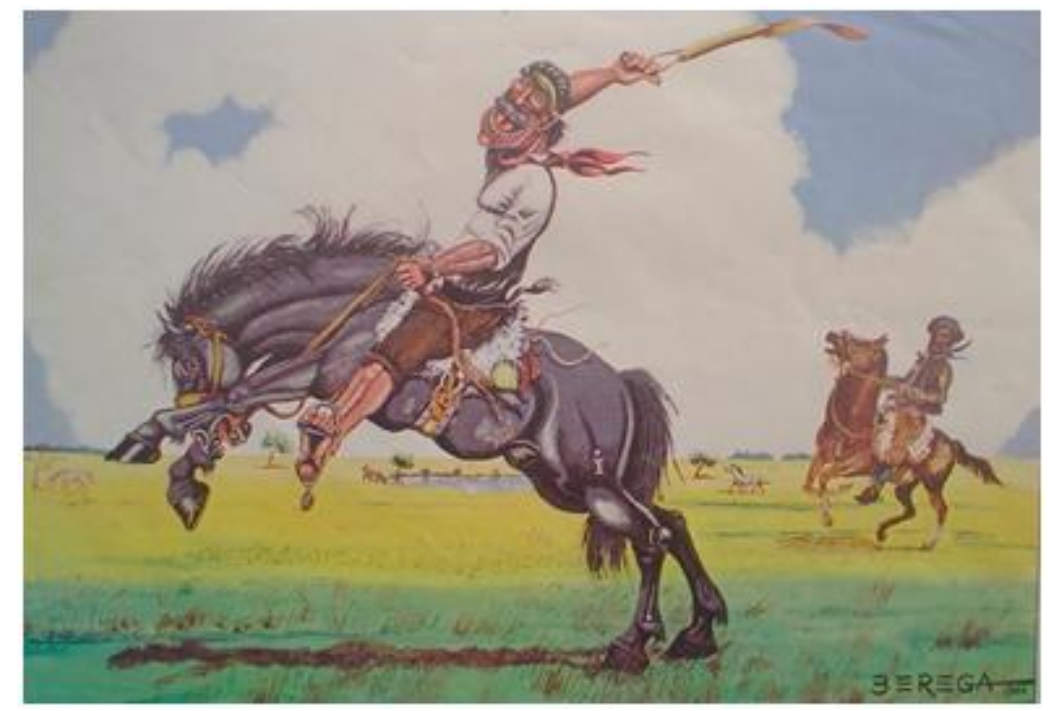

Ilustração de Berega para o Calendário Ipiranga, 1982. Fonte: https://goo.gl/Frl71s 
Figura 9: Aplicau a bellaguiar

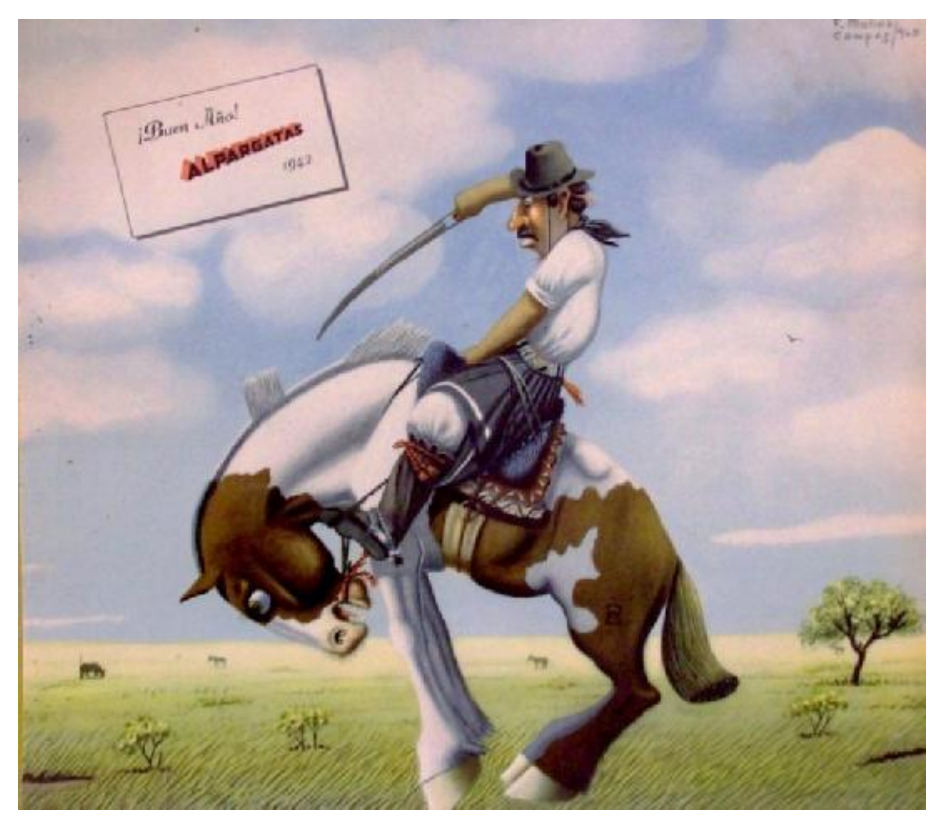

llustração de Molina para o Alamanaque Alpargatas, 1942. Fonte: https://goo.gl/GKxHnp

Nas duas imagens os signos se repetem, direcionam o observador a interpretação da virilidade manifesta pela força e pela potência que o próprio movimento alude. Numa análise comparada com a obra de Jaques Louis Davi, a concepção de alento e energia concentram-se na figura do cavalo empinando sobre as patas traseiras, à medida que Napoleão exibe uma postura tranquila de domínio,usando o próprio braço como instrumento de poder e direção, desconsiderando a precariedade em que se "encontra" a dupla. Fisicamente, a postura seria impossível devido a verticalidade da montanha, mas visualmente, a posição potencializa o poder e a altivez de Bonaparte.

Nas imagens de Molina e Berega a vasta paisagem pampiana domina o horizonte. A amplidão do espaço repercute também a ideia de solidão, não melancólica ou nostálgica, senão plena de liberdade. Assim como Napoleão, os peões dominam claramente o ambiente, as figuras secundarias que eventualmente aparecem apenas reforçam a liderança dos personagens nas obras.

$\mathrm{Na}$ produção cinematográfica de Sofia Coppola, "Maria Antonieta" - uma referência do kitsch contemporâneo, como proclamou Lipovestky -, os signos se repetem em releitura típica. 
Em quase todos os domínios o kitsch ganha terreno, impõe sua estética sobrecarregada e eclética, ao mesmo tempo em que se beneficia de uma ampla corrente de reabilitação. Ela invade o mobiliário, (...) a arquitetura pósmoderna, o cinema (Almodóvar, Sofia Coppola, Baz Luhrmann) (LIPOVESTKY, 2015, p. 303).

Figura 10: Napoleão cruzando os

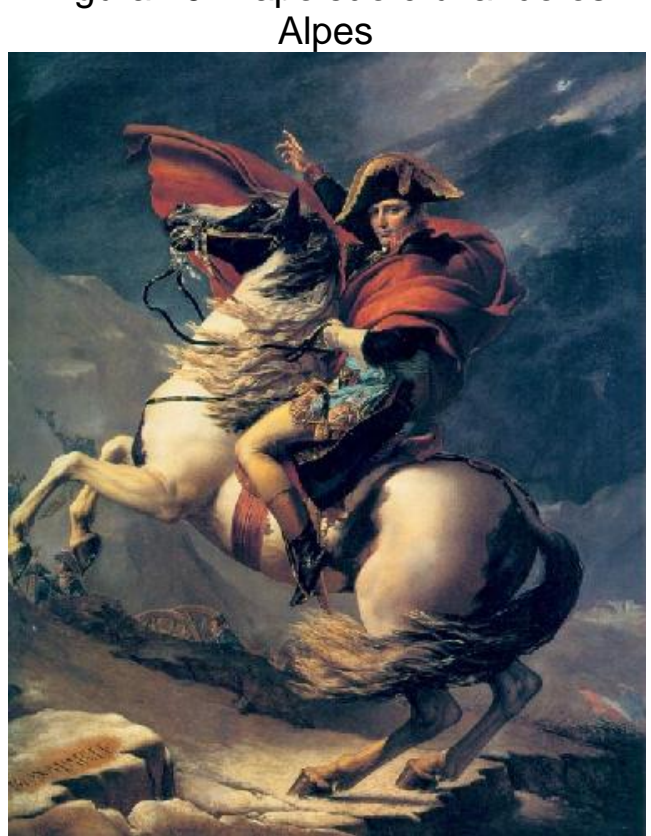

Jacques-Louis David, 1800-1803.

Fonte: https://goo.gl/Bd5YzE

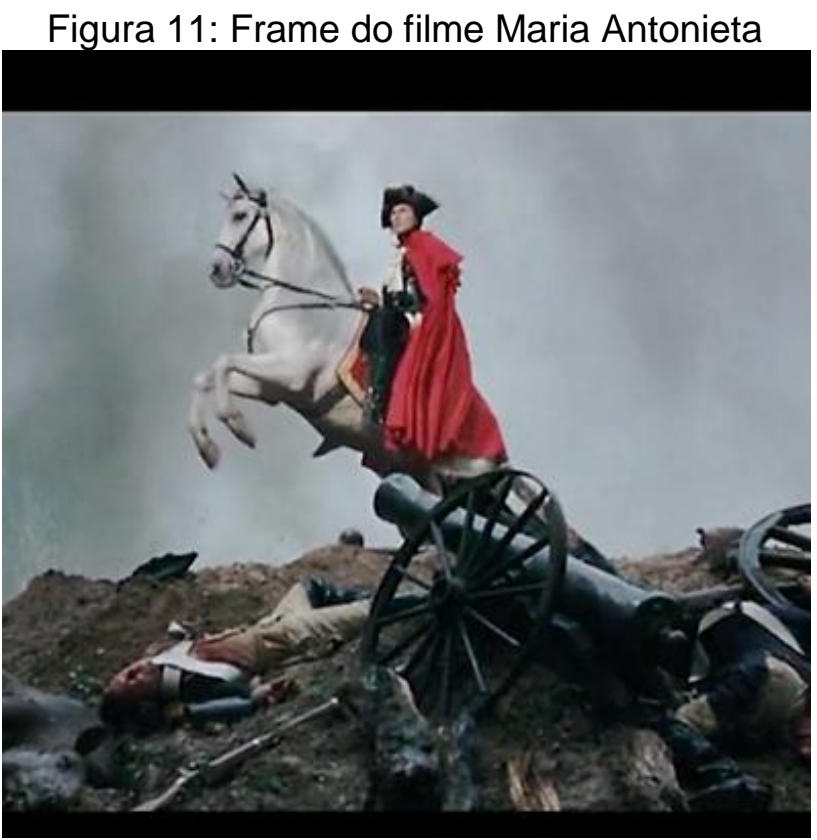

Direção de Sofia Coppola, 2007. Fonte: https://goo.gl/hFTQ2l

O estilo rococó, seguido por Copolla no discurso visual do filme pode ser tão Kitsch quanto o clichê no qual converteu-se imagem de Napoleão e seu cavalo branco. Por outro lado e não excludente, permanece o imaginário social sobre esses ícones de majestade e força, ecoando na leitura dos observadores o impacto desejado pelos artistas.

Para Baczko (1984 pg. 311), os imaginários sociais se assentam num simbolismo que é, simultaneamente, obra e instrumento. De modo que um signo produz outro em cadeia significante. Estes, "investidos pelo imaginário correspondem a outros tantos símbolos" tem a função de classificar e introduzir valores, modelando os comportamentos individuais e coletivos. 
A imagem do homem sobre o cavalo, repercutindo uma ideia sígnica de poder, vem de longa data e pode ser asseverada pelo discurso que ostentam as estátuas equestres, desde a Roma Antiga. Compõe pelo simulacro, um extrato do mundo emocional que a estética kitsch pretende exercer.

Nas estátuas equestres - a exemplo das representações de políticos romanos, do Gattamelata, de Donatello, do Monumento a Felipe IV, de Pietro Tacca etc. -, fica visível o poder do conjunto "sujeito e cavalo", em uma parceria que se harmoniza pela grandeza e força que conforma. Esse é um dos padrões sígnicos que invadiu o imaginário social,condensando uma série de mensagens significantes, mesmo que o cavaleiro seja um anônimo, como nas obras de Molina e Berega, carregam um conjunto simbólico que permitem realizar tais conjecturas.

\section{Considerações finais}

As relações significativas são essenciais ao pensamento humano, não se pode decodificar o meio senão através dos signos que este emana. Neste contexto, cada objeto demanda significados e as representações formam as frações por meio das quais configura-se o entorno.

As imagens, em especial, são poderosos meios de ressignificação simbólica. Cada figuração carrega no seu bojo um conjunto de redes significativas interligadas a quantidade e qualidade do repertorio iconográfico do observador. Como elucida Mangel,

\footnotetext{
Quando lemos imagens- de qualquer tipo, sejam pintadas, esculpidas, fotografadas, edificadas ou encenadas-, atribuímos a elas o caráter temporal da narrativa. Ampliamos o que é limitado por uma moldura para um antes e um depois, e por meio da arte de narrar histórias (sejam de amor ou ódio) conferimos a imagem imutável uma vida infinita e inesgotável (MANGEL, 2002, p. 27).
}

As obras e Molina e Berega, pertencem a uma imaginário social que representa uma coletividade particular. Elas são fruídas pelos sujeitos que se identificam por sua 
rede de signos com os sentidos reproduzidos pelas imagens. Também recriações de imaginários dos próprios artistas, bem como de todo o entorno dos qual foram capazes de retirar elementos.

Seria um equívoco afirmar que a produção de ambos ecoa tão-somente nos imaginários gauchescos. O que conecta e aciona emoções no público são os significados presentes na vida cotidiana, nos desejos humanos, na própria dinâmica da relação com a ambiência. Os componentes simbólicos podem pertencer à outras culturas e à outras épocas, mas forçosamente trazem consigo as qualidades mais peculiares e caras aos sujeitos. Por esse nicho a estética kitsch se infunde, como um amálgama que articula as peças, não pela qualidade técnica ou pela falta dela, pela banalidade ou pelos excessos visuais, mas porque aciona emoções e memórias.

\section{Referências}

BACZKO, Bronislaw. Imaginação Social. In: Enciclopédia EINAUDI. Vol. I (Memória-História). Lisboa: Imprensa Nacional e Casa da Moeda, 1984. p. 296-332.

BERGER, John. Modos de Ver. Rio de janeiro, Rocco, 1999.

CARVALHO, Francismar A. O Conceito de Representações Coletivas segundo Roger Chartier.In: Diálogos DH/PPHU/UEM, v. 9, n. 1, 2005. p. 143-165.

CHARTIER, Roger. As origens culturais da Revolução Francesa. São Paulo: Editora da Unesp, 2009.

CHARTIER, Roger. O mundo como Representação. In: Estudos avançados. Vol 5 no. 11 São Paulo jan/Abr. 1991.

CUNHA, Euclides da. Os Sertões: campanha de Canudos. Edição, prefácio, cronologia, notas e índice Leopoldo M. Bernucci. São Paulo: Ateliê Editorial, 2001.

ECO, Umberto. A História da Feiura. Rio de Janeiro: Record, 2007. LIPOVESTKY, Gilles. A Felicidade Paradoxal: ensaios sobre a sociedade do hiperconsumo. Lisboa: Edições 70, 2015.

MANGUEL, Alberto. Lendo Imagens. São Paulo: Cia Das letras, 2001. 
MORRONE, J.J. América do Sul e geografia da vida: Comparação de algumas propostas de regionalização. In: CARVALHO, C.J.B., Almeida, E.A.B. (eds.). Biogeografia da América do Sul: Padrões e processos. São Paulo: Editora Roca, 2011.

SANTAELLA, Lucia. Semiótica Aplicada. São Paulo, Cengage Learning, 2010.

SOLOMON, Robert C. In defense of sentimentality. Oxford University Press, 2004.

SPIVEY, Nigel J. How Art Made the World: A Journey to the Origins of Human Creativity. Nova lorque: Basic Books, 2005.

TORTATO, B. A.; AHLERT, J. A embriaguez de consumo: uma introdução ao kitsch. In: Revista Asa-Palavra. Brumadinho: Ensino Superior-Periódicos/Faculdade ASA.v. 1, p. 163-168, 2015.

\section{Websites}

BEREGA, WebSite Oficial - Gaúchos e Cavalos para Sempre... gaúcho. Disponível em: http://www.berega.com.br/. Acesso em 9.mar.2017

MOLINA CAMPOS,Vida y Obra. Disponível em: http://www.molinacampos.net/molina-campos-vida-y-obra. Acesso em 13.mar.2017

KUNSTHISTORISCHES MUSEUM WIEN. Disponível em: http://www.khm.at/en/.

Acesso em 30.mar.2017

SAVE VENICE INC. Disponível em:https://savevenice.org/. Acesso em 20.mar.2017

HALS, Frans. The complete Works. Disponível em: http://www.franshals.org/. Acesso em 11.mar.2017

L'HISTOIRE PAR L'IMAGE. Disponível em: https://www.histoireimage.org/. Acesso em 10.mar.2017

YOUTUBE. Disponível em: https://www.youtube.com/. Acesso em 20.mar.2017 